\title{
Microperimetric evaluation of chronic central serous chorioretinopathy after half-dose photodynamic therapy
}

This article was published in the following Dove Press journal:

Clinical Ophthalmology

15 October 2012

Number of times this article has been viewed

Kyoko Fujita'

Kei Shinoda ${ }^{1,2}$

Celso Soiti Matsumoto ${ }^{2}$

Yutaka Imamura ${ }^{3}$

Etsuko Tanaka ${ }^{4}$

Yoshihiro Mizutani'

Atsushi Mizota ${ }^{2}$

Mitsuko Yuzawa'

'Department of Ophthalmology, Surugadai Nihon University Hospital, Tokyo, ${ }^{2}$ Teikyo University School of Medicine, University Hospital Itabashi, Tokyo, ${ }^{3}$ Teikyo University School of Medicine, University Hospital Mizonokuchi, Kanagawa, ${ }^{4}$ Kyorin University School of Medicine, Mitaka, Japan

Correspondence: Kei Shinoda Department of Ophthalmology, Teikyo University School of Medicine, Kaga 2-I I-I, Itabashi-ku Tokyo,

173-8606, Japan

Tel +8I 33964 I 225

$\mathrm{Fax}+8 \mathrm{I} 33964$ I402

Email shinodak@med.teikyo-u.ac.jp
Background: The purpose of this study was to determine baseline clinical factors to correlate the outcome of half-dose verteporfin photodynamic therapy (PDT) in eyes with chronic central serous chorioretinopathy (CSC).

Methods: In this prospective, non-comparative, interventional case series, 14 eyes of 14 patients with chronic CSC who received half-dose verteporfin PDT were examined. The bestcorrected visual acuity (BCVA), macular sensitivity in the central 4, 8, and 12 degrees, and fixation stability were evaluated at baseline and at months $1,3,6$, and 12 after half-dose verteporfin PDT. Macular sensitivity and fixation stability were determined by MP-1 microperimetry.

Results: Mean retinal sensitivity in the central 4 and 8 degrees was significantly better at 1 , 3, 6, and 12 months after half-dose verteporfin PDT than at baseline. BCVA was significantly better after half-dose verteporfin PDT but only after 3 months. Fixation was relatively unstable in three eyes at baseline, but became stable at 12 months. BCVA at 12 months was significantly correlated with pre-PDT fixation stability $(\mathrm{r}=0.7120, P=0.0038)$.

Conclusion: Half-dose verteporfin PDT results in a significant increase in mean central retinal sensitivity for at least 12 months. Our findings indicate that microperimetry is a useful method for evaluating the functional benefits of half-dose verteporfin PDT in eyes with chronic CSC.

Keywords: microperimetry, fixation point, retinal sensitivity, photodynamic therapy, chronic central serous chorioretinopathy

\section{Introduction}

Central serous chorioretinopathy (CSC) is characterized by a serous retinal detachment in the macular area. Patients complain of a blurred area in the central or paracentral visual field. ${ }^{1}$ In the majority of patients, CSC is self-limiting, and their visual acuity recovers fully after resolution of the serous retinal detachment. ${ }^{1}$ However, visual acuity only reflects foveal function, and patients, even those with good visual acuity, can have a reduction in other visual functions, eg, contrast sensitivity, color discrimination, dark-adaptation, focal macular electroretinograms, and macular sensitivity. ${ }^{2-7}$

The MP-1 microperimeter (Nidek, Vigonza, Italy) is a relatively new instrument that couples digital fundus imaging with automated microperimetry. ${ }^{8}$ Recent MP-1 studies have clearly shown that eyes with resolved CSC can have significantly lower central retinal sensitivity, even after good central visual acuity had been obtained. ${ }^{9,10}$

Photodynamic therapy (PDT) with verteporfin has been used to treat CSC, and positive visual outcomes have been reported in most patients. ${ }^{11-13}$ The good results have been attributed to short-term choriocapillaris hypoperfusion and long-term choroidal vascular remodeling, which leads to a reduction in choroidal congestion, vascular hyperperme- 
ability, and extravascular leakage. ${ }^{13-16}$ Because conventional PDT can also result in complications, such as retinal pigment epithelium atrophy, choroidal ischemia, and secondary choroidal neovascularization, ${ }^{12,13}$ several authors have used safety-enhanced PDT with half the conventional dose of verteporfin $\left(3 \mathrm{mg} / \mathrm{m}^{2}\right)^{17-19}$ or with reduced fluence of $25 \mathrm{~J} / \mathrm{cm}^{2}$ for 83 seconds, ie, $300 \mathrm{~mW} / \mathrm{cm}^{2}$, in eyes with chronic CSC. ${ }^{20-22}$ They found sufficient photodynamic effects on the choroidal vasculature and a good visual outcome with minimal retinal damage. Improvement of macular sensitivity using MP-1 before and after half-dose verteporfin PDT in eyes with chronic CSC has recently been reported. ${ }^{19,22}$ We have also reported on the effectiveness and safety of half-dose verteporfin PDT improvements of retinal sensitivity for at least 3 months in patients with chronic chorioretinopathy. ${ }^{23}$ The purpose of this study was to evaluate the effectiveness of half-dose verteporfin PDT on macular sensitivity in eyes with chronic CSC after 1 year. In addition, we determined the correlations between visual acuity, retinal sensitivity, and fixation stability.

\section{Materials and methods}

This was a prospective, consecutive, open-label, noncomparative, interventional study conducted at the Surugadai Nihon University Hospital. Sixteen eyes from 16 patients with chronic CSC were examined in a prospective manner. ${ }^{23}$ Among these, a complete set of data was obtained for 14 patients over a follow-up period of 1 year were included in the study. The demographics of the patients are shown in Table 1. Inclusion criteria were the presence of subretinal fluid involving the fovea in optical coherence tomographic
(OCT) images and a serous retinal detachment of at least 6 months in duration. Patients who had evidence of choroidal neovascularization, polypoidal choroidal vasculopathy, or other maculopathy documented by fluorescein angiography or indocyanine green angiography were excluded. Patients who had had treatments such as focal laser coagulation or intravitreal injection of anti-vascular endothelial growth factor agents were also excluded.

Diagnosis of CSC was based on the presence of serous macular detachment with leakage from the retinal pigment epithelium in the fluorescein angiography images. A medical and ocular history was obtained from each patient, and a complete ophthalmic examination, including determination of best-corrected visual acuity (BCVA), slit-lamp biomicroscopy, OCT, fluorescein angiography, and indocyanine green angiography was performed. All OCT examinations were carried out using the Heidelberg Spectralis OCT instrument (Heidelberg Engineering, Heidelberg, Germany) at baseline, and 1, 3, 6, and 12 months after PDT. The procedures used conformed to the guidelines of the Declaration of Helsinki. Informed consent was obtained from all subjects after a complete explanation of the procedures to be used.

\section{Photodynamic therapy}

PDT was performed using a $3 \mathrm{mg} / \mathrm{m}^{2}$ body surface area of verteporfin (Visudyne, Novartis AG, Bülach, Switzerland) which is half the conventional dose of verteporfin. ${ }^{17-19,23}$ Verteporfin was infused over a 10-minute period followed by delivery of $50 \mathrm{~J} / \mathrm{cm}^{2}$ from a $689 \mathrm{~nm}$ laser system (Carl Zeiss, Dublin, CA) over an 83-second exposure period. The size of

Table I Demographics of the patients with central serous chorioretinopathy

\begin{tabular}{|c|c|c|c|c|c|c|c|c|}
\hline Case & Gender & Age (years) & Affected eye & Duration (months) & GLD $(\mu \mathrm{m})$ & VA (decimal) & LogMAR & Fixation** \\
\hline 1 & $\mathrm{~m}$ & 45 & $\mathrm{R}$ & 12 & 3800 & 0.9 & 0.05 & $S$ \\
\hline 2 & $\mathrm{~m}$ & 64 & $\mathrm{R}$ & 120 & 5100 & 0.7 & 0.15 & $S$ \\
\hline 3 & $\mathrm{~m}$ & 40 & $\mathrm{R}$ & 48 & 2700 & 1.0 & 0.00 & $S$ \\
\hline 4 & $\mathrm{~m}$ & 54 & $\mathrm{R}$ & 132 & 5900 & 1.5 & -0.18 & $S$ \\
\hline 5 & $\mathrm{~m}$ & 62 & $\mathrm{~L}$ & 13 & 5300 & 0.7 & 0.15 & $S$ \\
\hline 6 & $\mathrm{~m}$ & 57 & $\mathrm{R}$ & Unknown & 4500 & 0.15 & 0.82 & $\mathrm{R}$ \\
\hline 7 & $\mathrm{~m}$ & 55 & $\mathrm{R}$ & 12 & 4500 & 0.7 & 0.15 & $S$ \\
\hline 8 & $\mathrm{~m}$ & 45 & $\mathrm{R}$ & 72 & 4200 & 1.2 & -0.08 & $S$ \\
\hline 9 & $\mathrm{~m}$ & 41 & $\mathrm{R}$ & 6 & 4300 & 0.5 & 0.30 & $S$ \\
\hline 10 & $\mathrm{~m}$ & 44 & $\mathrm{~L}$ & 36 & 3500 & 0.2 & 0.70 & $\mathrm{R}$ \\
\hline II & $\mathrm{m}$ & 53 & $\mathrm{R}$ & 39 & 3100 & 0.5 & 0.30 & $\mathrm{R}$ \\
\hline 12 & $\mathrm{~m}$ & 50 & $\mathrm{~L}$ & 6 & 4900 & 0.7 & 0.15 & $S$ \\
\hline 13 & $\mathrm{~m}$ & 46 & $\mathrm{R}$ & 33 & 4000 & 0.9 & 0.05 & $S$ \\
\hline 14 & $\mathrm{~m}$ & 56 & $\mathrm{~L}$ & 60 & 5400 & 0.9 & 0.05 & $S$ \\
\hline Mean & & 50.9 & & 45.3 & 4371.4 & $0.65^{*}$ & 0.19 & \\
\hline SD & & 7.6 & & 41.5 & 910.1 & & 0.28 & \\
\hline
\end{tabular}

Notes: *Geometric mean; **S = stable; $\mathrm{R}=$ relatively unstable.

Abbreviations: GLD, greatest linear dimension = spot size; VA, visual acuity; m, male; SD, standard deviation 
the laser spot was the diameter of the region of indocyanine green hyperpermeability. After treatment, protective spectacles were given to the patients, and they were instructed to avoid strong light for 5 days.

\section{Assessment of location and stability of fixation by MP-I microperimetry}

Fundus-monitored microperimetry was performed with the MP-1. ${ }^{8,23}$ A 4-2 staircase strategy using a Goldmann III size stimulus was used, and 45 stimulus locations covering the central 12 degrees were tested by microperimetry (Figure 1, see the middle row of the center and right columns). The mean retinal sensitivities at 12 locations covering the central 4 degrees (central microperimetry, c4MP-1), 28 locations

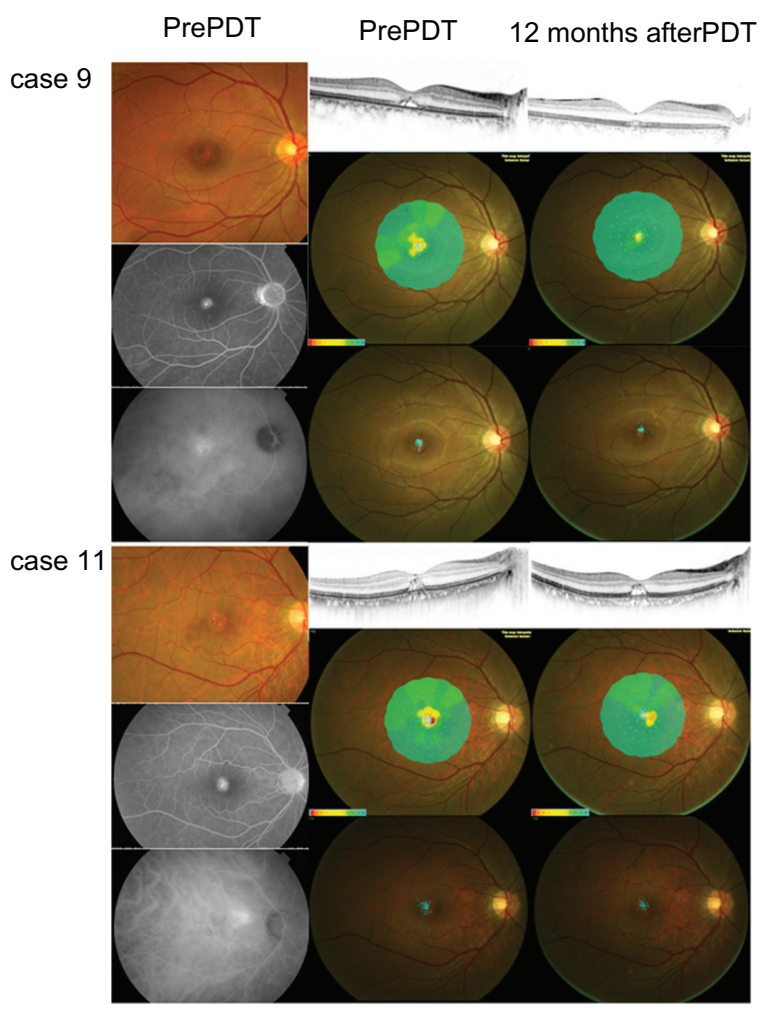

Figure I Representative cases with similar pretreatment findings but with different outcomes after half-dose verteporfin PDT.

Notes: The left column shows the fundus photographs (top), fluorescence angiographic images at a late phase (middle), and indocyanine green angiographic images at a late phase (bottom) for each case. The middle column shows a horizontally scanned optical coherence tomographic image (top), macular retinal sensitivity (middle), and fixation stability (bottom) at baseline for each case. The right column shows horizontally scanned optical coherence tomographic image (top), macular retinal sensitivity (middle), and fixation stability (bottom) 12 months after half-dose verteporfin PDT for each case. Fundus photography, fluorescein angiography, indocyanine green angiography, and optical coherence tomographic findings, and macular sensitivity, but not fixation stability, at baseline are similar in the two cases. The visual acuity at baseline was 0.5 in each case. The spot size for PDT was $4300 \mu \mathrm{m}$ for case 9 and $3100 \mu \mathrm{m}$ for case II. Twelve months after half-dose verteporfin PDT, the optical coherence tomographic findings and macular sensitivity was different although fixation stability became similar in both cases. Visual acuity was 0.9 in case 9 and 0.4 in case II.

Abbreviation: PDT, photodynamic therapy. covering the central 8 degrees (central microperimetry, c8MP-1), and at 45 locations covering the central 12 degrees (central microperimetry, c12MP-1) were determined.

A fixation cross was presented at a maximum luminance of MP-1. Subjects were asked to look at the center of the cross and were encouraged to use their peripheral vision if needed. Once the subjects had located the cross, the stability of fixation was measured for a period of 30 seconds. To determine the stability of fixation, movements of the fundus image were tracked while the patient tried to maintain continuous fixation on the target. The autotracking system calculated the horizontal and vertical shifts relative to a reference frame and drew a map of the patient's eye movements at $25 \mathrm{~Hz}$ throughout the examination.

The stability of fixation was based on the locations and movements using the MP-1 software, as recommended by Fujii et al. ${ }^{24}$ Fixation was defined as being stable when more than $75 \%$ of the fixation points were located within a predetermined 2 degree diameter circle centered on the gravitational center of all fixation points, regardless of the position of the foveal center. Location of fixation was classified as "relatively unstable" fixation when less than 75\% of fixation points were located within a 2 degree diameter circle, but more than $75 \%$ of fixation points were located within a 4 degree diameter circle. The fixation was classified as "unstable fixation" when less than $75 \%$ of the fixation points were located within a 4 degree circle. All patients were allowed one preliminary practice of the MP-1 to try to standardize the learning effect.

\section{Statistical analysis}

Paired $t$-tests were used to determine whether retinal sensitivity and BCVA in each post-treatment period were significantly different from corresponding values at baseline. Spearman's correlation of coefficient analysis was performed to determine the correlation between mean retinal sensitivity and BCVA. We also performed stepwise multiple regression analyses to determine if any pretreatment factors were significantly associated with post-PDT BCVA. Independent factors investigated in the analysis were age (years), greatest linear diameter of the choroidal hyperpermeability region (microns), fixation stability, baseline BCVA in logarithm of the minimum angle of resolution ( $\log M A R)$ units, and retinal sensitivity at 4, 8, and 12 degrees. The Bonferroni correlation was used to avoid type I error. Statistical significance was set at $P<0.0125$ for the $t$-tests because there were four comparisons and at 0.05 for the Spearman's correlation of coefficient analysis. 


\section{Results}

The CSC patients consisted of 14 men whose mean age was $51 \pm 7.6$ (range 40-64) years. Duration of symptoms was 6-132 months (Table 1). Serous retinal detachment was resolved 1 month after PDT in 11 eyes, but cases 6 and 11 had a reduction and flatter serous retinal detachment, which was still present 12 months after PDT.

Mean BCVA was 0.19 $\pm 0.28 \log$ MAR units at baseline, $0.18 \pm 0.29 \log$ MAR units at 1 month $(P>0.05), 0.11 \pm 0.28$ $\log$ MAR units $(P=0.01)$ at 3 months, $0.04 \pm 0.27 \log$ MAR units $(P=0.0002)$ at 6 months, and $0.03 \pm 0.26 \log$ MAR units $(P=0.002)$ at 12 months after PDT (Table 2 and Figure 2). At 12 months, all patients reported an improvement in their vision, but only five patients had an improvement of their BCVA by more than $0.2 \log$ MAR units.

Mean retinal sensitivity within the central 4 degrees (12 points) improved significantly from $7.42 \pm 4.75 \mathrm{~dB}$ at baseline to $11.31 \pm 4.51 \mathrm{~dB}$ at 1 month, $13.66 \pm 4.57 \mathrm{~dB}$ at 3 months, $14.39 \pm 4.97 \mathrm{~dB}$ at 6 months, and $15.19 \pm 4.84 \mathrm{~dB}$ at 12 months (Figure 3, $P<0.0125$ for all time points). Mean retinal sensitivity within the central 8 degrees (28 points) improved significantly from $10.03 \pm 4.45 \mathrm{~dB}$ at baseline to $13.11 \pm 3.88 \mathrm{~dB}$ at 1 month, $15.15 \pm 3.41 \mathrm{~dB}$ at 3 months, $15.68 \pm 3.84 \mathrm{~dB}$ at 6 months, and $16.48 \pm 3.49 \mathrm{~dB}$ at 12 months (Figure 3, $P<0.0125$ for all time points).

Mean retinal sensitivity within the central 12 degrees (45 points) improved significantly from $11.84 \pm 3.89 \mathrm{~dB}$ at baseline to $14.26 \pm 3.15 \mathrm{~dB}$ at 1 month, $15.95 \pm 2.80 \mathrm{~dB}$ at 3 months, $16.41 \pm 3.11 \mathrm{~dB}$ at 6 months, and $17.11 \pm 2.82 \mathrm{~dB}$ at 12 months (Figure 3, $P<0.0125$ at 3, 6, and 12 months).
Fixation was central in all eyes for all measurements. Fixation was stable in eleven cases at baseline and relatively unstable in the other three cases $(6,10$, and 11). Fixation became stable at 1 month after PDT in cases 6 and 10, and at 12 months after PDT in case 11 (Table 2).

Significant correlations were found between the sensitivities of c12MP-1 and BCVA at 6 and 12 months, between the sensitivities of c8MP-1 and BCVA at 3, 6, and 12 months, and between the sensitivities of c4MP-1 and BCVA at 3 and 12 months.

Multiple regression analysis showed that among the independent factors, only fixation stability $(P=0.0038$, regression coefficient 0.357 , adjusted $\mathrm{R}^{2}=0.507$ ) was significantly associated with BCVA at 12 months.

We present two representative cases with different outcomes after half-dose verteporfin PDT, although several pretreatment findings were similar (Figure 1). The fundus appearance, fluorescein angiography and indocyanine green angiography findings, OCT findings, and macular sensitivity, but not fixation properties, in both cases were similar at baseline. However, the response to half-dose verteporfin PDT was very different.

\section{Discussion}

Our results showed that mean retinal sensitivity in the central 4 and 8 degrees was significantly better than baseline at 1 , 3, 6, and 12 months after half-dose verteporfin PDT in eyes with CSC. BCVA was also significantly better, but only after 3 months. Fixation was relatively unstable in three eyes at baseline but became stable at 12 months after PDT. These findings indicate that half-dose verteporfin PDT is effective

Table 2 Visual acuity in patients with central serous chorioretinopathy before and after half-dose photodynamic therapy

\begin{tabular}{|c|c|c|c|c|c|c|}
\hline \multirow[t]{2}{*}{ Case } & \multirow[t]{2}{*}{ Pretreatment } & \multicolumn{4}{|c|}{ After treatment } & \multirow[t]{2}{*}{ Period of stable fixation* } \\
\hline & & I month & 3 months & 6 months & I 2 months & \\
\hline I & 0.9 & 1.0 & 1.2 & 1.5 & 1.5 & Pre \\
\hline 2 & 0.7 & 0.6 & 0.6 & 0.8 & 0.7 & Pre \\
\hline 3 & 1.0 & 1.0 & 1.5 & 1.5 & 1.5 & Pre \\
\hline 4 & 1.5 & 1.2 & 1.5 & 1.5 & 1.5 & Pre \\
\hline 5 & 0.7 & 0.7 & 0.8 & 1.0 & 1.0 & Pre \\
\hline 6 & 0.15 & 0.1 & 0.15 & 0.2 & 0.2 & I month \\
\hline 7 & 0.7 & 1.0 & 1.0 & 1.5 & 1.5 & Pre \\
\hline 8 & 1.2 & 1.2 & 1.5 & 1.5 & 1.5 & Pre \\
\hline 9 & 0.5 & 0.7 & 0.8 & 0.9 & 0.9 & Pre \\
\hline 10 & 0.2 & 0.3 & 0.4 & 0.4 & 0.7 & I month \\
\hline II & 0.5 & 0.5 & 0.4 & 0.5 & 0.4 & 12 months \\
\hline 12 & 0.7 & 0.7 & 0.9 & 0.9 & 0.9 & Pre \\
\hline 13 & 0.9 & 0.9 & 1.0 & 1.0 & 1.5 & Pre \\
\hline 14 & 0.9 & 0.7 & 1.0 & 1.5 & 1.2 & Pre \\
\hline Geomean** & 0.649 & 0.657 & 0.785 & 0.917 & 0.942 & \\
\hline
\end{tabular}

Notes: *The point when stable fixation was observed. 'pre' means the stable fixation was first observed already at pre-PDT.

Abbreviations: geomean, geometric mean; PDT, photodynamic therapy. 


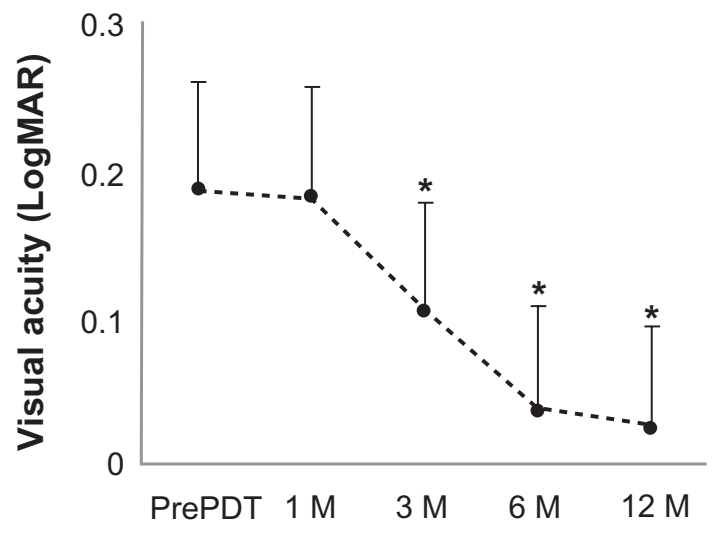

Figure 2 Mean best-corrected visual acuity in logarithm of the minimum angle of resolution units before and after half-dose verteporfin PDT in patients with chronic central serous chorioretinopathy.

Notes: The best-corrected visual acuity is significantly better at 3 months than at baseline. ${ }^{*} P<0.0125$; Bars are the standard deviations.

Abbreviation: $M$, months; PDT, photodynamic therapy.

in improving not only sensitivity in the macular region, but also the stability of fixation.

We found that measuring retinal sensitivity and fixation stability by microperimetry was probably more important than determining just the visual acuity when evaluating CSC patients. This was because visual acuity is measured using high contrast letters under bright light conditions and does not represent the visual tasks of CSC patients in their daily lives.

We found that not only BCVA but also retinal sensitivity and fixation stability improved significantly after half-dose verteporfin PDT. In addition, retinal sensitivity improved significantly at just 1 month after PDT, while

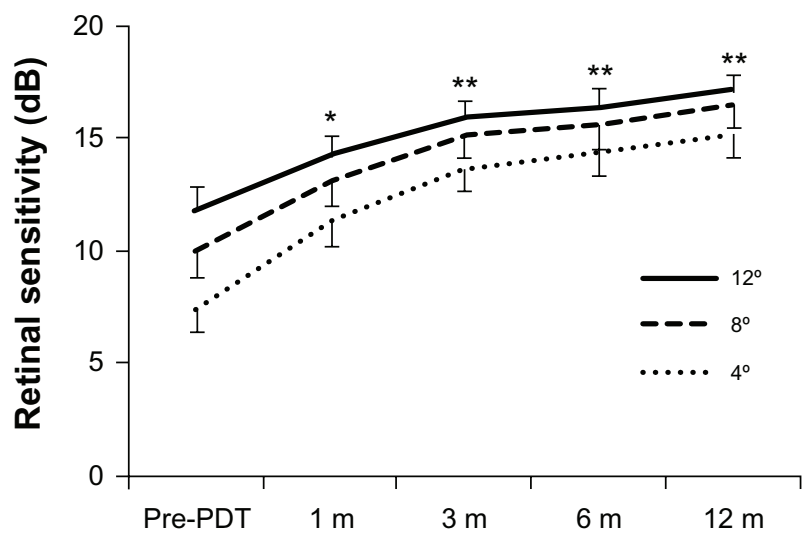

Figure 3 Mean retinal sensitivity in the central retinal areas of 4, 8, and I 2 degrees before and after half-dose verteporfin PDT in patients with central serous chorioretinopathy. Notes: There is significant improvement in sensitivity compared with baseline after I month. *P $<0.0125$ in comparison of mean retinal sensitivity from central 4 and 8 degrees at I month after treatment. $* * P<0.0125$ in comparison of mean retinal sensitivity from central 4, 8, and 12 degrees at 3,6, and 12 months. Bars show standard errors of the means.

Abbreviation: M, months; PDT, photodynamic therapy.
BCVA improved only after 3 months. It is interesting that all of the patients reported an improvement in their vision and symptoms.

Senturk et al ${ }^{19}$ reported that both visual acuity and retinal sensitivity significantly improved at 1,3 , and 6 months after PDT in eyes with CSC. Reibaldi et $\mathrm{a}^{22}$ reported that both visual acuity and retinal sensitivity significantly improved at 3 and 12 months after PDT in eyes with CSC.

Our study had a small sample number, no control subjects, and different durations of symptoms. These factors may partly explain the discrepancies between our results and those of Senturk et al ${ }^{19}$ and Reibaldi et al. ${ }^{22}$ However, these are quantitative differences and do not invalidate the effectiveness of half-dose verteporfin PDT. Reibaldi et $\mathrm{al}^{22}$ also reported that retinal sensitivity in the central 12 degrees at 12 months after PDT was significantly higher in low fluencetreated eyes than in standard fluence-treated eyes.

A significant correlation was found between retinal sensitivity and BCVA as early as 6 months after treatment, and the difference decreased with time. Sensitivity in c4MP-1 were significantly correlated with BCVA at 3 months. This was expected because the retinal sensitivity from the smaller central area tends to reflect central foveal function. It was interesting that retinal sensitivity was lowest in the most central area and decreased with increasing eccentricity, ie, c4MP-1 < c8MP-1 < c12MP-1. One explanation for this is that the central retina might be more susceptible to the effects of serous retinal detachment because the mean greatest linear diameter in our cases was approximately $4700 \mu \mathrm{m}$, which covered the central retinal area containing the area of MP-1 measurements.

Sekine et $\mathrm{al}^{25}$ investigated the relationship between retinal sensitivity measured by Humphrey visual field analyzer and morphological changes in eyes with CSC. They found a significant correlation between retinal sensitivity and height of the serous retinal detachment. It was striking that this correlation, like that of c4MP- $1<\mathrm{c} 8 \mathrm{MP}-1<\mathrm{c} 12 \mathrm{MP}-1$, lasted throughout the follow-up period of 12 months in our study. We suggest that the long-lasting sensitivity reduction was due to PDT. However, Ozdemir et al ${ }^{9}$ reported that retinal sensitivity was lower in the central 10 degrees in eyes with resolved CSC than in control eyes. The sensitivity reduction in the central area was present even after spontaneous resolution.

Because visual acuity is good in cases of CSC, it is reasonable that fixation stability would also be good. In other words, unstable fixation might indicate greater impairment of central retinal function. Although our findings should be carefully interpreted because of a small sample size, it is 
interesting that fixation stability at baseline was significantly correlated with final visual acuity at 12 months. Two cases with similar visual acuity and OCT appearances at baseline had different courses after PDT.

There are several studies describing the importance of fixation stability in evaluation of macular function after therapeutic intervention in retinal diseases. ${ }^{21,26,27}$ Further studies are needed to determine whether fixation stability can be a predictive factor for BCVA after half-dose verteporfin PDT in eyes with CSC.

Our study has several limitations, such as a relatively small sample size and no control group. Further prospective studies with control groups in larger series will be necessary to determine the efficacy of half-dose verteporfin PDT or any other treatment on the retinal sensitivity and fixation stability in eyes with CSC.

In conclusion, retinal sensitivity and BCVA improved or was maintained after half-dose verteporfin PDT. Our findings indicate that it is important to determine retinal sensitivity and fixation stability when evaluating the effect of PDT on eyes with CSC. These parameters may be useful indicators of the effectiveness of treatment.

\section{Acknowledgment}

This study was supported by Research on Sensory and Communicative Disorders from the Ministry of Health, Labor, and Welfare, Japan, and is registered at clinicaltrials. gov (NCT01434095).

\section{Disclosure}

The authors report no conflicts of interest in this work.

\section{References}

1. Spaide RF. Central serous chorioretinopathy. In: Holz FG, Spaide RF, editors. Medical Retina. Heidelberg, Germany: Springer Verlag; 2004.

2. Nagata M, Honda Y. Studies on local electric response of the human retina. VI. Macular ERGs of a typical central serous retinopathy. Nippon Ganka Gakkai Zasshi. 1970;74:957-964. Japanese.

3. Folk JC, Thompson HS, Han DP, Brown CK. Visual function abnormalities in central serous retinopathy. Arch Ophthalmol. 1984;102: 1299-1302.

4. Chuang EL, Sharp DM, Fitzke FW, et al. Retinal dysfunction in central serous retinopathy. Eye (Lond). 1987;1:120-125.

5. Miyake Y, Shiroyama N, Ota I, Horiguchi M. Local macular electroretinographic responses in idiopathic central serous chorioretinopathy. $\mathrm{Am} \mathrm{J}$ Ophthalmol. 1988;106:546-550.

6. Marmor MF, Tan F. Central serous chorioretinopathy: bilateral multifocal electroretinographic abnormalities. Arch Ophthalmol. 1999; 117:184-188.

7. Maaranen TH, Tuppurainen KT, Mäntyjärvi MI. Color vision defects after central serous chorioretinopathy. Retina. 2000;20: 633-637.
8. Springer C, Bültmann S, Völcker HE, Rohrschneider K. Fundus perimetry with the Micro Perimeter 1 in normal individuals: comparison with conventional threshold perimetry. Ophthalmology. 2005;112: 848-854.

9. Ozdemir H, Karacorlu SA, Senturk F, Karacorlu M, Uysal O. Assessment of macular function by microperimetry in unilateral resolved central serous chorioretinopathy. Eye (Lond). 2008;22: 204-208.

10. Ojima Y, Tsujikawa A, Hangai M, et al. Retinal sensitivity measured with the micro perimeter 1 after resolution of central serous chorioretinopathy. Am J Ophthalmol. 2008;146:77-84.

11. Yannuzzi LA, Slakter JS, Gross NE, et al. Indocyanine green angiographyguided photodynamic therapy for treatment of chronic central serous chorioretinopathy: a pilot study. Retina. 2003;23:288-298.

12. Cardillo Piccolino F, Eandi CM, Ventre L, Rigault de la Longrais RC, Grignolo FM. Photodynamic therapy for chronic central serous chorioretinopathy. Retina. 2003;23:752-763.

13. Chan WM, Lam DS, Tam BS, Liu DT, Chan CK. Choroidal vascular remodeling in central serous chorioretinopathy after indocyanine green guided photodynamic therapy with verteporfin: a novel treatment at the primary disease level. Br J Ophthalmol. 2003;87: $1453-1458$.

14. Schlötzer-Schrehardt U, Viestenz A, Naumann GO, Laqua H, Michels S, Schmidt-Erfurth U. Dose-related structural effects of photodynamic therapy on choroidal and retinal structures of human eyes. Graefes Arch Clin Exp Ophthalmol. 2002;240:748-757.

15. Schmidt-ErfurthU,LaquaH, Schlotzer-SchrehardU, Schlötzer-SchrehardU, Viestenz A, Naumann GO. Histopathological changes following photodynamic therapy in human eyes. Arch Ophthalmol. 2002;120: 835-844.

16. Lee JY, Chae JB, Yang SJ, Kim JG, Yoon YH. Intravitreal bevacizumab versus the conventional protocol of photodynamic therapy for treatment of chronic central serous chorioretinopathy. Acta Ophthalmol. 2011;89:e293-e294.

17. Chan WM, Lai TY, Lai RY, Liu DT, Lam DS. Half-dose verteporfin photodynamic therapy for acute central serous chorioretinopathy: one-year results of a randomized controlled trial. Ophthalmology. 2008;115:1756-1765.

18. Lim JW, Kang SW, Kim YT, Chung SE, Lee SW. Comparative study of patients with central serous chorioretinopathy undergoing focal laser photocoagulation or photodynamic therapy. $\mathrm{Br} J$ Ophthalmol. 2011;95:514-517.

19. Senturk F, Karacorlu M, Ozdemir H, Karacorlu SA, Uysal O. Microperimetric changes after photodynamic therapy for central serous chorioretinopathy. Am J Ophthalmol. 2011;151:303-309.

20. Reibaldi M, Boscia F, Avitabile T, et al. Low-fluence photodynamic therapy in longstanding chronic central serous chorioretinopathy with foveal and gravitational atrophy. Eur J Ophthalmol. 2009;19:154-158.

21. Reibaldi M, Cardascia N, Longo A, et al. Standard-fluence versus low-fluence photodynamic therapy in chronic central serous chorioretinopathy: a nonrandomized clinical trial. Am J Ophthalmol. 2010;149:307-315.

22. Reibaldi M, Boscia F, Avitabile T, et al. Functional retinal changes measured by microperimetry in standard-fluence vs low-fluence photodynamic therapy in chronic central serous chorioretinopathy. Am J Ophthalmol. 2011;151:953-960.

23. Fujita K, Yuzawa M, Mori R. Retinal sensitivity after photodynamic therapy with half-dose verteporfin for chronic central serous chorioretinopathy: short-term results. Retina. 2011;31:772-778.

24. Fujii GY, De Juan E Jr, Humayun MS, Sunness JS, Chang TS, Rossi JV. Characteristics of visual loss by scanning laser ophthalmoscope microperimetry eyes with subfoveal choroidal neovascularization secondary to age-related macular degeneration. Am J Ophthalmol. 2003;136:1067-1078. 
25. Sekine A, Imasawa M, Iijima H. Retinal thickness and perimetric sensitivity in central serous chorioretinopathy. Jpn J Ophthalmol. 2010;54:578-583.

26. Pearce E, Sivaprasad S, Chong NV. Comparing fixation location and stability in patients with neovascular age-related macular degeneration treated with or without ranibizumab. Eye (Lond). 2010;25: $149-153$
27. Senturk F, Ozdemir H, Karacorlu M, Karacorlu SA, Uysal O. Microperimetric changes after intravitreal triamcinolone acetonide injection for macular edema due to central retinal vein occlusion. Retina. 2010;30:1254-1261.

\section{Publish your work in this journal}

Clinical Ophthalmology is an international, peer-reviewed journal covering all subspecialties within ophthalmology. Key topics include: Optometry; Visual science; Pharmacology and drug therapy in eye diseases; Basic Sciences; Primary and Secondary eye care; Patien Safety and Quality of Care Improvements. This journal is indexed on

Submit your manuscript here: http://www.dovepress.com/clinical-ophthalmology-journal

\section{Dovepress}

PubMed Central and CAS, and is the official journal of The Society of Clinical Ophthalmology (SCO). The manuscript management system is completely online and includes a very quick and fair peer-review system, which is all easy to use. Visit http://www.dovepress.com/ testimonials.php to read real quotes from published authors. 